\title{
Cirujano General: nueva época
}

\section{Cirujano General: new era}

T a Asociación Mexicana de Cirugía General celebra la reanudación de la publicación de su órgano oficial de difusión, la revista Cirujano General.

Hoy iniciamos una nueva etapa con otro Consejo Editorial, integrado por cirujanos empeñados en restituir la calidad de la revista, plenamente identificados con el proyecto de nuestra Asociación, con la experiencia suficiente para sacarlo adelante y lograr el objetivo de alcanzar la indización.

Apreciarán cambios substanciales en su diseño: una nueva portada con los colores corporativos propios de nuestra Asociación, un formato de lectura novedoso y visualmente atractivo, así como la aparición de nuestro logotipo oficial actualizado.

Hoy nuevamente invitamos a todos los cirujanos a compartir sus experiencias en Cirujano General, a participar en su publicación, sabedores de que contarán siempre con el apoyo irrestricto del Consejo Editorial para perfeccionar los aspectos editoriales de sus trabajos.

\section{Abilene C. Escamilla Ortiz}

